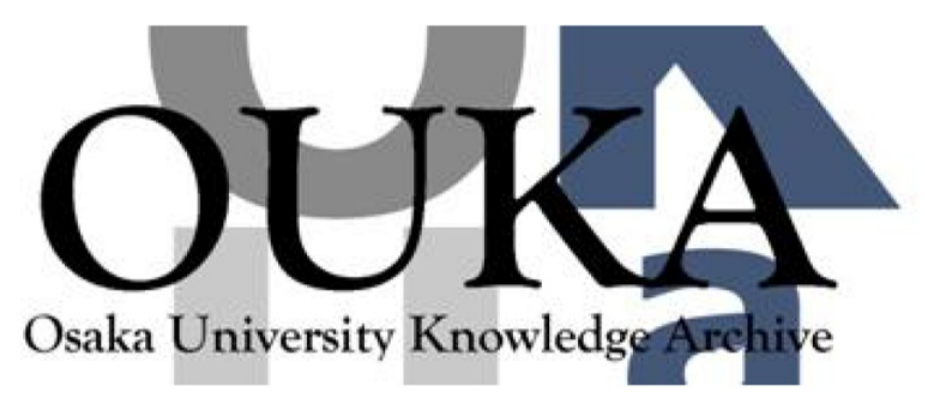

\begin{tabular}{|c|l|}
\hline Title & $\begin{array}{l}\text { Miscibility and phase separation in LC } \\
\text { semiconductor blends }\end{array}$ \\
\hline Author(s) & Shimizu, Y.; Matsuda, Y.; Nakao, T. et al. \\
\hline Citation & $\begin{array}{l}\text { Proceedings of SPIE - the International Society } \\
\text { for Optical Eng ineering. 9004 p. 900408-1- } \\
\text { p.900408-8 }\end{array}$ \\
\hline Issue Date & $2014-02-19$ \\
\hline oaire:version & VoR \\
\hline URL & https://hdl. handle. net/11094/75928 \\
\hline rights & \\
\hline Note & \\
\hline
\end{tabular}

Osaka University Knowledge Archive : OUKA

https://ir. Library. osaka-u. ac. jp/

Osaka University 


\title{
Miscibility and Phase Separation in LC Semiconductor Blends
}

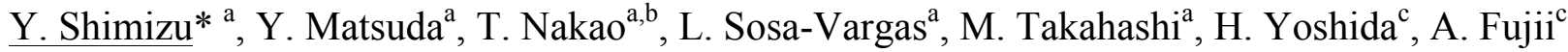 \\ and M. Ozaki ${ }^{\mathrm{c}}$ \\ ${ }^{a}$ Synthetic Nano-Function Materials Group, Research Institute for Ubiquitous Energy Devices, \\ National Institute of Advanced Industrial Science and Technology, Kansai Center (AIST-Kansai), \\ Midorigaoka, Ikeda, Osaka 563-8577, JAPAN; \\ ${ }^{\mathrm{b}}$ Department of Materials Chemistry, Faculty of Science and Engineering, Ryukoku University, \\ Seta, Otsu, Shiga 520-2194, JAPAN \\ ${ }^{\mathrm{c}}$ Division of Electrical, Electronic and Information Engineering, Graduate School of Engineering, \\ Osaka University, 2-1 Yamada-oka, Suita, Osaka, 565-0871, JAPAN
}

\begin{abstract}

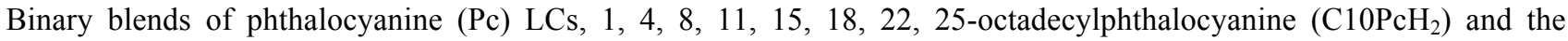
corresponding $\mathrm{Zn}$ complex $(\mathrm{C} 10 \mathrm{PcZn})$ were studied which have the identical hexagonal columnar $\left(\mathrm{Col}_{\mathrm{h}}\right)$ mesophase and the same order of carrier mobility $\left(\sim 10^{-1} \mathrm{~cm}^{2} \mathrm{~V}^{-1} \mathrm{~s}^{-1}\right)$ in the mesophase. The phase diagram shows a complete miscibility in the $\mathrm{Col}_{\mathrm{h}}$ mesophase and no eutectic point was detected. The carrier mobility evaluated by Time-Of-flight (TOF) technique goes down to $10^{-2} \mathrm{~cm}^{2} \mathrm{~V}^{-1} \mathrm{~s}^{-1}$ in $\mathrm{Col}_{\mathrm{h}}$ phase of the initial blends prepared by solution mixing. However, the treatment of these binary systems with repetitive heating and cooling gives recovering of carrier mobility to the original level, though their HOMO and LUMO levels are slightly different in these two mesogenic Pcs. These results indicate that two types of single component column form a hexagonal array in mesophase. Also the blends with PCBM were studied on carrier mobility as well as miscibility and phase separation.
\end{abstract}

Keywords: liquid crystalline semiconductor, phthalocyanine, carrier mobility, printed electronics, organic solar cell

\section{INTRODUCTION}

"Miscibility" is one of the characteristic properties of liquid crystal. Two liquid crystalline compounds exhibiting the identical liquid crystalline phase in thermodynamical point of view could be mixed at a molecular level to form the identical liquid crystalline phase at any component ratio. This requires a condition that the mixing does not induce any additional intermolecular specific interactions. On the other hand, "phase separation" is also a phenomenon easily emerged in liquid crystal because of the dynamic state of molecular aggregation where mesogenic molecules form single-component domains in a separate way and/or part by part to each component. These two properties are significantly important for spontaneous formation of hierarchical or periodical structures in molecular blends. In other word, miscibility and phase separation are strongly useful tools for constructing complex structures of molecular aggregation and therefore, it should be based on the molecular design for expecting functional properties such as bulk heterojunction (BHJ) active layer in organic photovoltaics (OPV).

When one prepares the blend with two mesogenic compounds exhibiting, for example, nematic phase, one can make a binary phase diagram showing miscibility and a typical diagram is shown in Fig.1. At any component ratio, one sees a temperature range of nematic phase. Two clearing points of the compounds can be connected with a strait line as an ideal manner, while the both melting points decreases to give an eutectic point at a component ratio, which is, in principle, predicted with Le Chatlier-Schröder equation (Eq. 1 \& 2). At the eutectic point, the widest range of temperature is seen for LC phase, meaning that the temperature range of LC phase can be extended by mixing two mesogenic compounds. This has been utilized to control the temperature range of LCs in display applications.

Emerging Liquid Crystal Technologies IX, edited by Liang-Chy Chien, Antonio M. Figueiredo Neto,

Kristiaan Neyts, Masanori Ozaki, Proc. of SPIE Vol. 9004, 900408 · (c) 2014 SPIE

CCC code: $0277-786 \mathrm{X} / 14 / \$ 18 \cdot$ doi: $10.1117 / 12.2042321$

Proc. of SPIE Vol. $9004900408-1$ 
$-\left(\Delta \mathrm{H}_{\mathrm{A}} / \mathrm{R}\right)\left(1 / \mathrm{T}-1 / \mathrm{T}_{\mathrm{A}}\right)=\ln \mathrm{X}_{\mathrm{A}}$

$-\left(\Delta H_{B} / R\right)\left(1 / T-1 / T_{B}\right)=\ln X_{B}$

$\mathrm{X}_{\mathrm{A}}+\mathrm{X}_{\mathrm{B}}=1$

$\mathrm{X}_{\mathrm{A}}, \mathrm{X}_{\mathrm{B}}$ : component ratios of compound $\mathrm{A}$ and $\mathrm{B}$

For discotic columnar mesophase, miscibility is more sensitive to molecular size and intermolecular interaction than for calamitic lower ordered phases. ${ }^{[1]}$ In highly ordered mesophase, miscibility condition is less allowed. However, it is not so simple for the case of organic semiconductor. For a mixture in which two compounds have the difference in the electronic level (HOMO and LUMO), the carrier mobility is decreased because two compounds meet directly in molecular level. ${ }^{[2]}$ Hopping conduction is seriously depressed. This means that the structure (molecular order) of such a mixture should be controlled to avoid this electronic interference to keep at least the original level of carrier mobility for each compound. Therefore, two compounds that should be mixed to fabricate a thin film active layer in device make its molecular order independently without electronic interference. This would be realized in a way of phase separation. Generally, chemical structure of discogen shows a combination of rigid aromatic core and flexible tails peripherally attached to the core, like a nano-wire in an electronic point of view. In columnar stacks of discogenic molecules, the center of column is occupied with stacking aromatics forming an electronic charge transport path and is covered with insulating alkyl chains. Considering this characteristic image of columnar structure, one can expect that if single component columns for two discogens form a columnar mesophase with a dispersion of columnar level, it would not cause the depression of charge transport efficiency.

When 1D-charge transport takes place along the columnar axis and the axis aligns in a perpendicular way (homeotropic alignment) to the substrate, ${ }^{[3]}$ this geometry of sandwich-type cell is good for thin film solar cell. ${ }^{[4]}$ In the active layer of organic thin film solar cell, $\mathrm{p}$ - and $\mathrm{n}$ - type of semiconductors are mixed to give $\mathrm{p} / \mathrm{n}$ heterojunction where charge separation takes place to generate hole and electron following migration of excitons generated by photoabsorption. In a BHJ active layer, exciton migration path, $\mathrm{p} / \mathrm{n}$ heterojunction, and charge transport path have to be designed and fabricated. Furthermore, such a structure should be spontaneously formed. Especially, it is strong requirement in Printed Electronics. Most of BHJ-OPV studies reported so far have not yet clarified the structure of $\mathrm{p} / \mathrm{n}$ junction in the layer as polymer semiconductors are used. In other words, it has not been controlled in a molecular level. The nano-scale structure in BHJ layer would be accessible by use of small molecule semiconductors. In particular, self-organization property of small molecules should be essentially important in terms of spontaneous formation of structure.

Recent studies on BHJ-type organic solar cells propose that interdigitated geometries of $p$ and n-types of semiconductors should be promising to attain the higher performance as OPV cells (Fig. 2) ${ }^{[5]}$ and self-assembling nature of liquid crystals should be important and useful character to realize a spontaneous formation of such a structure.

On the other hand, phthalocyanine is one of the trustful molecule in practical application as pigment and dye and has been studied as a semiconductor for organic photovoltaics due to its strong photoabsprption in visible region.

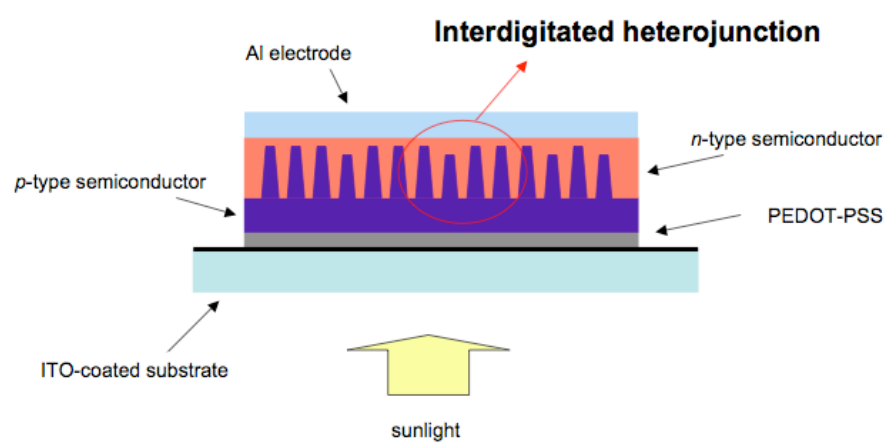

Figure 2: A schematic drawing of a proposed interdigitated structure of a bulk heterojunction active layer in organic thin film solar cells. 


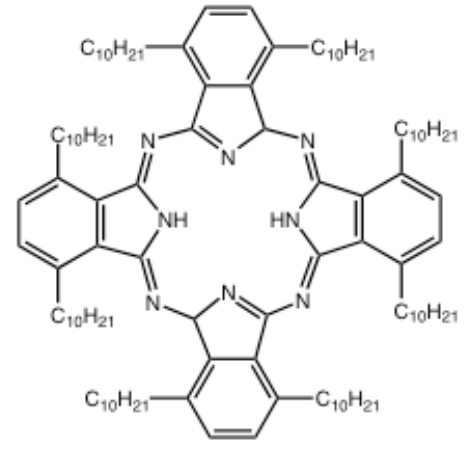

$\mathrm{C}_{10 \mathrm{PCH}_{2}}$

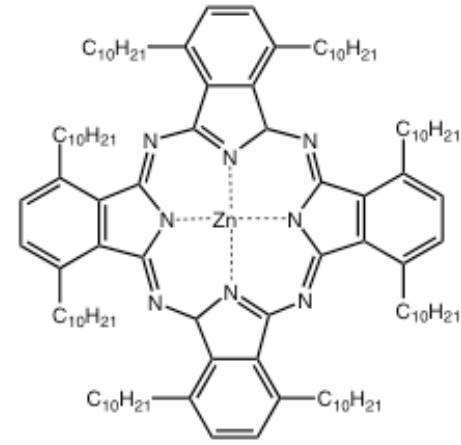

C10PcZn

FIGURE 3 : Chemical structures of $\mathrm{C} 10 \mathrm{PcH}_{2}$ and $\mathrm{C} 10 \mathrm{PcZn}$ used in this work and their phase transition seqeunces.

Recently, Iino et al. found that $1,4,8,11,15,18,22,25$-octaoctylphthalocyanine $\left(\mathrm{C} 8 \mathrm{PcH}_{2}\right)$ exhibits an ambipolar nature of charge transport in the hexagonal disordered columnar $\left(\mathrm{Col}_{\mathrm{hd}}\right)$ mesophase, while phthalocyanine $(\mathrm{Pc})$ is recognized as a p-type semiconductor ${ }^{[6]}$. Also the mobilities are rather fast in the order of $10^{-1} \mathrm{~cm}^{2} \mathrm{~V}^{-1} \mathrm{~s}^{-1}$, exhibiting field-independent property and a slight or non-dependency on temperature which are of typical for liquid crystalline semiconductors ${ }^{[7]}$. We reported ambipolar nature of carrier mobility with so high drift mobility for the poly-crystalline films $\left(1.4 \mathrm{~cm}^{2} \mathrm{~V}^{-1} \mathrm{~s}^{-1}\right)$ of the hexyl homologue $\left(\mathrm{C} \mathrm{PcH}_{2}\right) \cdot{ }^{[8]} \mathrm{Also} \mathrm{C}_{6} \mathrm{PcH}_{2}$ was applied to thin film solar cells as a p-type semiconductor for the bulk heterojunction system with PCBM $\left([6,6]\right.$-phenyl $\mathrm{C}_{71}$ butyric acid methyl ester) to give a rather high performance as solution-processed organic solar cells with low molecular weight organic semiconductors (power conversion efficiency: $3.1 \%$, external quantum efficiency: $>70 \%$ at the Q-band) ${ }^{[9]}$ Also the addition of C6PcH2 into conventional P3HT/PCBM system was found to give the better performance due to the better light harvesting which was ascribed to the strong photoabsorption of Pcs. ${ }^{[10]}$

In this communication, miscibility of two phthalocyanine $\mathrm{LCs}\left(\mathrm{C} 10 \mathrm{PcH}_{2}\right.$ and $\left.\mathrm{C} 10 \mathrm{PcZn}\right)$ were studied and the carrier mobility was measured by TOF technique to discuss the mixing status in both columnar and crystalline solid phases. It is worthwhile to notice that an important property of Pc molecules is the fact that Pc molecule could form metal complexes with a variety of metal species. This means $\mathrm{Pc}$ is a molecule that could exhibit rich light-harvesting properties due to the wide range of wavelength that could be attined by chemical modifications and metal ligations. Therefore, it is an important notice that blending some of phthalocyanine compounds leads to the better light-harvesting ability toward organic photovoltaics.

The phthalocyanine LCs used in this work are of non-peripheral type as shown in Fig. 3. The connecting position of alkyl tails to phthalocyanine ring is not commonly seen most peripheral site. Therefore, steric problem gets remarkable when the molecules stack to form a columnar structure. In fact, even for the shorter homologue such as $\mathrm{C} \mathrm{PcH}_{2}$, no evidence could be detected in X-ray diffraction measurements for the presence of stacking periodicity along the columnar axis. The phase sequence is shown in Table 1. Both $\mathrm{C}_{10 \mathrm{PcH}_{2}}$ and $\mathrm{C} 10 \mathrm{PcZn}$ exhibit hexagonal columnar $\left(\mathrm{Col}_{\mathrm{h}}\right)$ mesophase ${ }^{[1]]}$ and the charge transport is ambipolar similar to $\mathrm{C} 6$ and $\mathrm{C} 8 \mathrm{PcH}_{2}$.

Table 1 Phase transitions of $\mathrm{C}_{10 \mathrm{PcH}_{2}}$ and $\mathrm{C} 10 \mathrm{PcZn}$

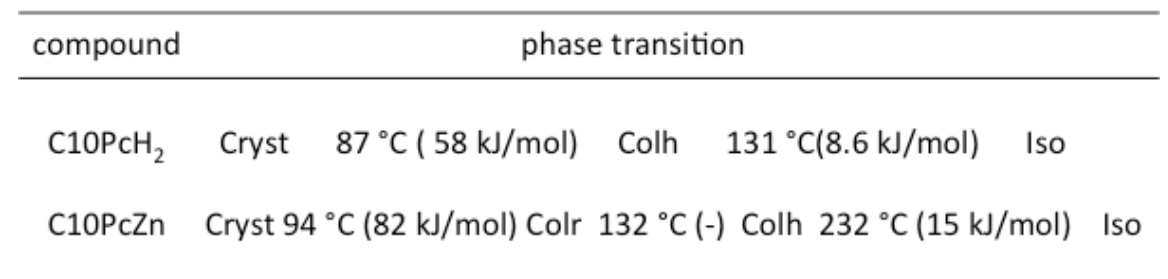



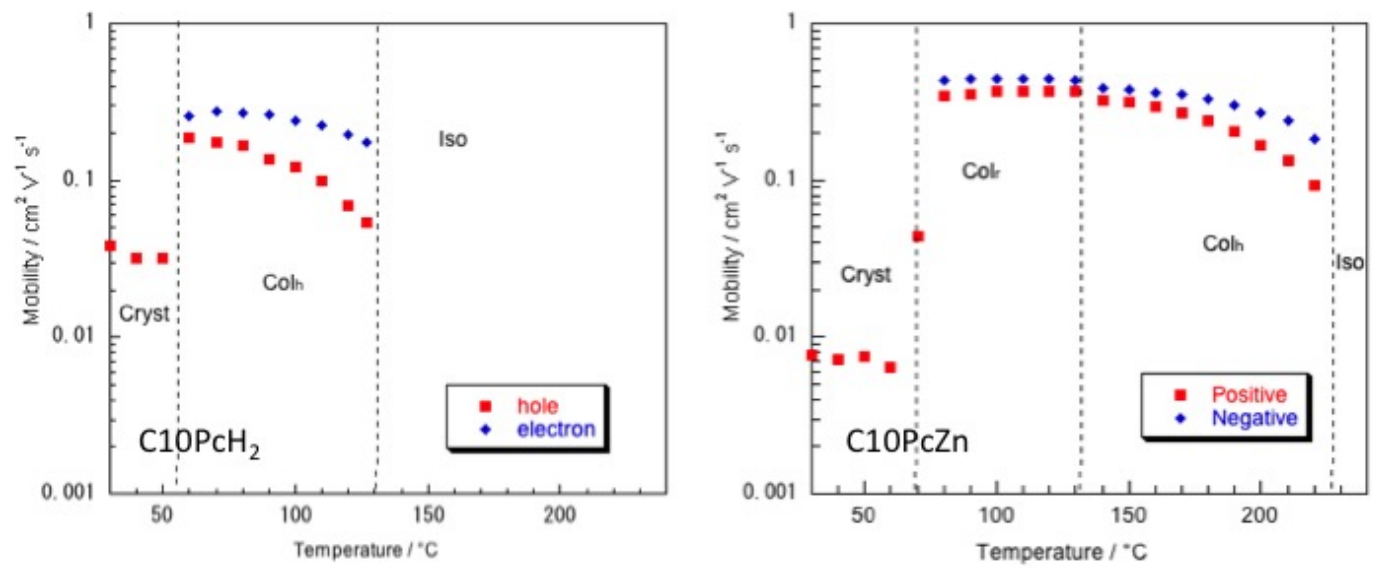

FIGURE 4 : Temperature dependence of hole and electron mobilities for $\mathrm{C}_{10 \mathrm{PcH}_{2}}$ and $\mathrm{C} 10 \mathrm{PcZn}$. Applied field : $10 \mathrm{kV} \mathrm{cm}^{-1}$.

Temperature dependence of carrier mobility for $\mathrm{C}_{10 \mathrm{PcH}_{2}}$ and aaC10 $\mathrm{PcZn}$ are shown in Fig. 4. Both hole and electron mobilities are temperature-dependent and the mobility decreases as temperature goes up. The carrier mobility is in the order of $10^{-1} \mathrm{~cm}^{2} \mathrm{~V}^{-1} \mathrm{~s}^{-1}$ in the $\mathrm{Col}_{\mathrm{h}}$ mesophase, which is the same order for the $\mathrm{Col}_{\mathrm{h}}$ mesophase of other homologues $(\mathrm{C} 8$ and $\mathrm{C} 6)$. Interestingly for $\mathrm{C} \mathrm{PcH}_{2}, \mathrm{C} 10 \mathrm{PcH} 2$ and $\mathrm{C} 10 \mathrm{PcZn}$, the electron mobility in the $\mathrm{Col}_{\mathrm{h}}$ mesophase is higher than the hole one.

\section{EXPERIMENTAL}

\subsection{Syntheses and purifications of the compounds}

$\mathrm{C} 10 \mathrm{PcH}_{2}$ was synthesized according to the literature with slight modifications ${ }^{[11]}$ and $\mathrm{C} 10 \mathrm{PcZn}$ was prepared by chelating reaction of $\mathrm{C} 10 \mathrm{PcH}_{2}$ with zinc acetate. The products were fully purified by column chromatography (silica-gel

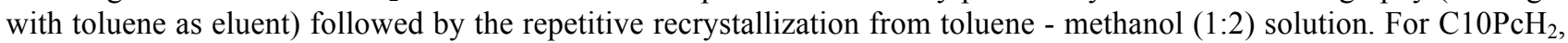
treatments with a chelating reagent was carried out to remove contaminant ionic metal species. The purity of compounds was checked by TOF measurement to see the saturation of transient photo-current decay curves as well as their carrier mobility. Purification process is so important as it affect the resultant photo-decay curves and carrier mobility. ${ }^{[12]}$

\subsection{Characterization of mesomorphism}

The phase transition temperatures and enthalpy changes were measured by differential scanning calorimetry (DSC, TA instrument DSC2920) and from microscopic observations of the optical textures (Olympus BH2 and Mettler FP90 hot stage). The mesophases were identified by X-Ray diffraction in the temperature range of the mesophase using a Rigaku RINT 2000 equipped with a hand-made hot stage.

\subsection{Charged carrier mobility of mesophase}

The carrier mobility in mesophase and crystalline phase was determined by Time-Of-flight (TOF) technique. ${ }^{[13]}$ The cell is of sandwich-type consisting of two ITO-coated glass plates as the electrodes (effective area of the electrode : $5 \mathrm{~mm}$ x $5 \mathrm{~mm}$ ) and polyimide film (Toray Kapton ${ }^{\circledR}$ with $12.5 \mu \mathrm{m}$ ) as spacer. The actual cell gaps were evaluated by an interference technique of light transmittance The compound was injected by capillarity action at the temperature above the isotropization. A $\mathrm{N}_{2}$-pulsed laser $(337 \mathrm{~nm}, 800 \mathrm{ps})$ was used for the photocarrier generation. The transient photocurrents were detected by a digital oscilloscope (HP, infinum) with the help of a wide band preamplifier (NF electronics instruments, BX-31A). The mobility, $\mu$ was calculated by the equation below,

$$
\mu=d^{2} / V \tau_{s}
$$


where $d$ is the sample thickness, $V$ the applied bias and $\tau_{s}$ the transit time.

Both compounds tend to spontaneously align in a homeotropic way for the $\mathrm{Col}_{\text {hd }}$ phase on cooling from the Iso phases between glass and ITO-coated glass substrates and this is the similar tendency to $\mathrm{C} 10$ - and $\mathrm{C} 8-\mathrm{PcH}_{2}$.

\section{RESULTS AND DISCUSSION}

\subsection{Miscibility}

Fig. 5 shows a binary phase diagram of $\mathrm{C}_{10 \mathrm{PcH}_{2}}$ and $\mathrm{C} 10 \mathrm{PcZn}$. One can see a linear correlation for the clearing point and the $\mathrm{Col}_{h}$ mesophase is observed at any component ratio. This indicates that two species of molecules are dispersed in a molecular level and no strong and additional intermolecular interactions take place by mixing. Consequently, complete miscibility is observed, though the clearing enthalpy values of these compounds show a certain difference $\left(8.6 \mathrm{~kJ} / \mathrm{mol}\right.$ and $15 \mathrm{~kJ} / \mathrm{mol}$ for $\mathrm{C} 10 \mathrm{PcH}_{2}$ and C10PcZn, respectively).

On the other hand, the melting line is approximately linear and no sign is found for the eutectic drop in temperature. This may indicate that the mixture forms a kind of solid solution in the crystalline solid. The powder XRD studies indicate that in this crystalline phase of the mixtures has the similar arrangement of molecules to that in the $\mathrm{Col}_{\mathrm{h}}$ mesophase, meaning hexagonal arrays of columns are still remained, though the phase transition enthalpies show a certain gap (58 $\mathrm{kJ} / \mathrm{mol}$ and $82 \mathrm{~kJ} / \mathrm{mol}$ for $\mathrm{C} 10 \mathrm{PcH}_{2}$ and $\mathrm{C} 10 \mathrm{PcZn}$, respectively) .

For the miscibility shown in $\mathrm{C}_{10 \mathrm{PcH}_{2}} /$ C10PcZn system, one can postulate two extreme situations of molecular blend. One is a simple molecularly dispersive system of $\mathrm{C} 10 \mathrm{PcH}_{2}$ and $\mathrm{C} 10 \mathrm{PcZn}$ and another is a blend of single-component columns forming hexagonal array f columns in a segregated way (Fig. 6).

\subsection{Carrier mobility}

Fig. 7 shows temperature dependence of carrier mobility for $\mathrm{C} 10 \mathrm{PcZn} / \mathrm{C} 10 \mathrm{PcH}_{2}$ system. The carrier mobility gets lowered in the blends. Temperature dependence of carrier mobility in the $\mathrm{Col}_{\mathrm{h}}$ mesophase is weakly temperaturedependent and it is in the order of $10^{-2} \mathrm{~cm}^{2} \mathrm{~V}^{-1} \mathrm{~s}^{-1}$. For the $\mathrm{Col}_{\mathrm{h}}$ mesophase of the mixtures also a strong tendency for spontaneous homeotropic alignment was observed in the cells (ITO-ITO sandwich-type).

It was found that the both hole and electron mobilities are reduced to the order of $10^{-2} \mathrm{~cm}^{2} \mathrm{~V}^{-1} \mathrm{~s}^{-1}$. However, this is not so drastic decrease of mobility, considering that the charge transfer rate between two molecules of which HOMO and LUMO energy levels are different is strongly affected by the energy gaps to provide shallow traps and recombination sites. In fact, photoelectron spectroscopy measurements of $\mathrm{C} 10 \mathrm{PcZn}$ and $\mathrm{C}_{10 \mathrm{PcH}_{2}}$ revealed that $\mathrm{HOMO}$ and LUMO 

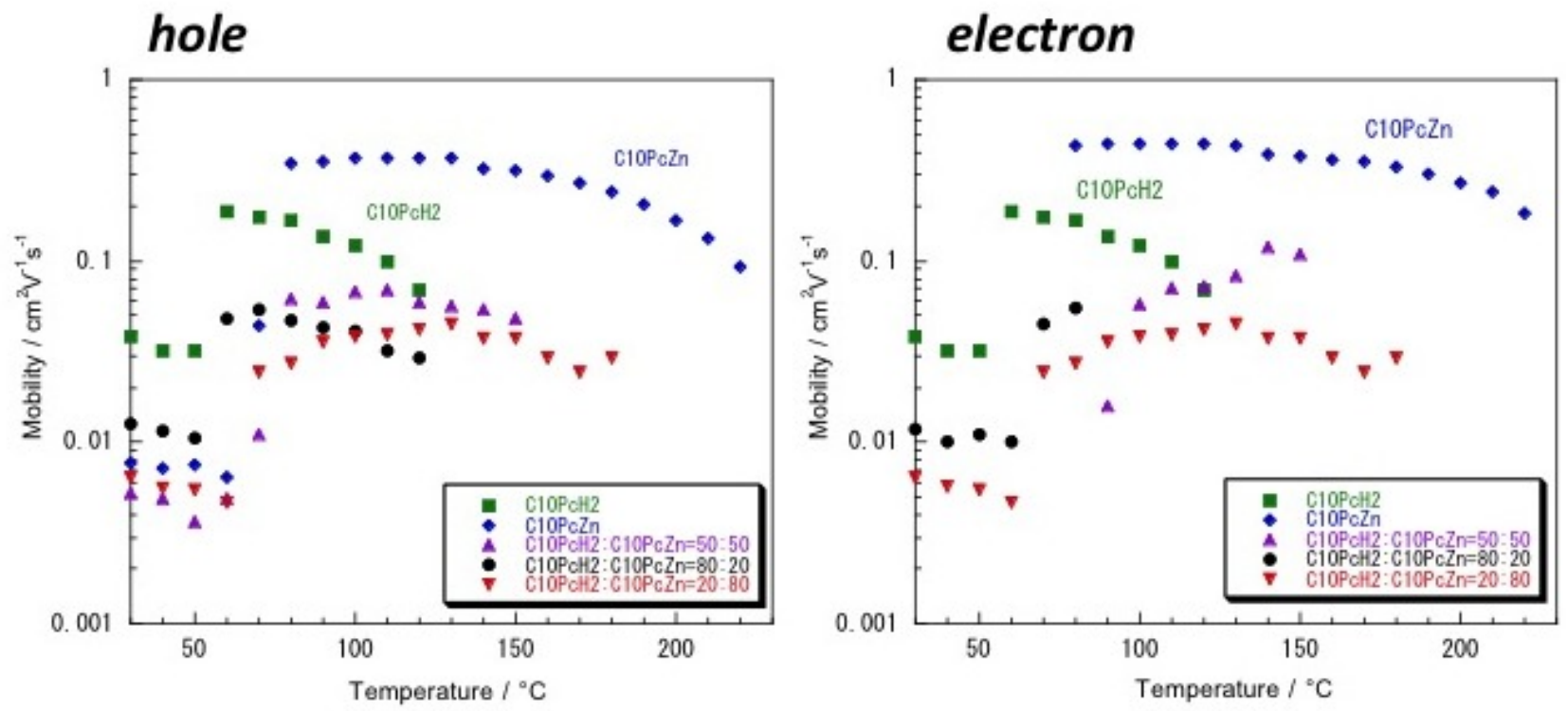

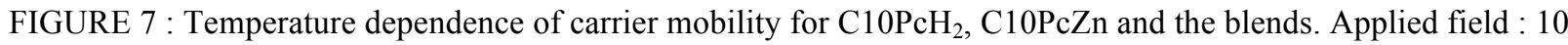
$\mathrm{kV} / \mathrm{cm}$.

levels of $\mathrm{C} 10 \mathrm{PcZn}$ are -5.15 and $-3.53 \mathrm{eV}$, respectively and -5.03 and $-3.51 \mathrm{eV}$ for $\mathrm{C} 10 \mathrm{PcH}_{2}$, respectively. This means that $\mathrm{C} 10 \mathrm{PcZn}$ could behave as a weak electronic acceptor and $\mathrm{C} 10 \mathrm{PcH}_{2}$ as a donor in this blend. Therefore, the fact that the reduced mobility in the order of $10^{-2} \mathrm{~cm}^{2} \mathrm{~V}^{-1} \mathrm{~s}^{-1}$ indicates that a certain length of successive charge hopping path is still maintained even after mixing these two columnar mesogens. However, contamination of one compound in a column of the counterpart discogen surely takes place.

The blends prepared by removing the solvent under a reduced pressure sometimes show a complicated phase transition curve on the $1^{\text {st }}$ heating in DSC measurements. The second and third heating runs in heating and cooling cycles show a steady state of phase transition curve, meaning that the better mixing could be attained by repetitive cooling and heating treatments of blends.

The observed mobility shown in Fig. 7 was also variant by repetitive heating and cooling operations around the clearing point. As the number of cyclic operation is increases, the observed carrier mobility goes up to the original level shown by the single component samples as shown in Fig. 8. This result imply that segregated columns with the single
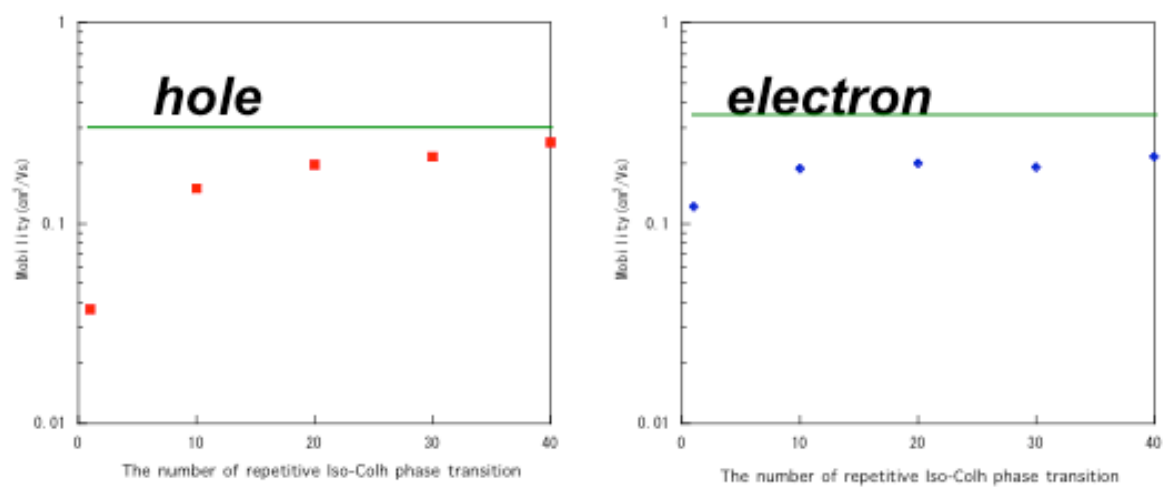

FIGURE 8 : Hole and electron mobilities vs. the number of heating and cooling cycle treated around the clearing point for the TOF cell with a $\mathrm{C} 10 \mathrm{PcH}_{2} / \mathrm{C} 10 \mathrm{PcZn}$ blend with 1:1 molar ratio. Measured at $165^{\circ} \mathrm{C}\left(\mathrm{Col}_{\mathrm{h}}\right.$ mesophase $)$. The horizontal line indicates the original level of carrier mobility in the $\mathrm{Col}_{\mathrm{h}}$ mesophase for both $\mathrm{C}_{10 \mathrm{PcH}_{2}}$ and C10PcZn. 
component form $\mathrm{Col}_{\mathrm{h}}$ mesophase, while the purification of molecularly stacked columns is proceeding on repetitive heating and cooling operations. As depicted in Fig. 6, freshly prepared blends by removing the solvent that would have columns where two discogens are mixed tend to stabilize to be a $\mathrm{Col}_{\mathrm{h}}$ mesophase in which two types of singlecomponent columns, one of which is made by $\mathrm{C}_{10} \mathrm{PcH}_{2}$ and another by $\mathrm{C} 10 \mathrm{PcZn}$, form a hexagonal arrangement. In other words, columns formed by $\mathrm{C}_{10} \mathrm{PcH}_{2}$ and by $\mathrm{C} 10 \mathrm{PcZn}$, independently, are coexisting as segregated columns (not alternative stacks of two types of mesogens) to form Colh mesophase and those play a certain role as a electronic hopping path for both hole and electron.

These results may provide a possibility to utilize "miscibility of columnar mesophases" toward the better performance of bulk heterojunction-type organic solar cells by way of the better light harvesting realized by molecular blending of liquid crystalline semiconductors.

\subsection{Miscibility of $\mathrm{C}_{10 \mathrm{PcH}_{2}}$ and $\mathrm{C10PcZn}$ with $\mathrm{PCBM}$}

Fig. 9 shows preliminary results of studies on the phase transition behavior of $\mathrm{C}_{10 \mathrm{PcH}_{2}} / \mathrm{PCBM}$ and $\mathrm{C} 10 \mathrm{PcZn} / \mathrm{PCBM}$ binary systems. In both cases, one sees the similar trend of miscibility. As the amount of PCBM increases, the clearing point of $\mathrm{Col}_{\mathrm{h}}$ mesophase decreases. This means the addition of PCBM leads to destabilization of Colh mesophase. However, the clearing point gets steady for the additional PCBM amount than $10 \mathrm{~mole} \%$, indicating that PCBM is resolved into the $\mathrm{Col}_{h}$ mesophase of $\mathrm{C}_{10 \mathrm{PcH}_{2}}$ and $\mathrm{C} 10 \mathrm{PcZn}$ up to $10 \mathrm{~mole} \%$ and the excess amount of PCBM is phaseseparated to generate small particles of PCBM in the $\mathrm{Col}_{h}$ phase. It was observed that the PCBM particles are fused into the isotropic liquid phase of Pc mesogens at the higher temperature. The elongation of alkyl chains may lead to the less miscibility of PCBM into the Col mesophase.

In the case of $\mathrm{C} \mathrm{PcH}_{2} / \mathrm{PCBM}$ system, thermal stability of columnar mesophase decreases as the PCBM amount is increased to show a disappearance of Col phase at 20-25 mole\% of PCBM and at the component ratio, the observed mobility (hole) shows the maximum that is over the carrier mobility of $\mathrm{C} 10 \mathrm{PcH}_{2}$ and by $\mathrm{C} 10 \mathrm{PcZn}{ }^{[14]}$ Interdigitation of linear chains of PCBM is expected to co-exist in the Col mesophase formed by Pc mesogens, though more than 25 mole $\%$ of PCBM is stoichiometrically necessary to align along the columnar axis to make a charge hopping path. It is also important to know the factors affect the miscibility of PCBM into discotic columnar arrays in mesophase in order to give an inspiration for the interdegitated p-n heterojunction in a BHJ active layer in OPV studies.

\section{SUMMARY}

Two mesogenic Pcs, $\mathrm{C} 10 \mathrm{PcH}_{2}$ and $\mathrm{C} 10 \mathrm{PcZn}$ exhibit a complete miscibility in the $\mathrm{Col}_{\mathrm{h}}$ mesophase. The hole and electron mobilities of the $\mathrm{Col}_{\mathrm{h}}$ mesophase for the $1: 1$ blend are reduced to the order of $10^{-2} \mathrm{~cm}^{2} \mathrm{~V}^{-1} \mathrm{~s}^{-1}$ though those of the pure
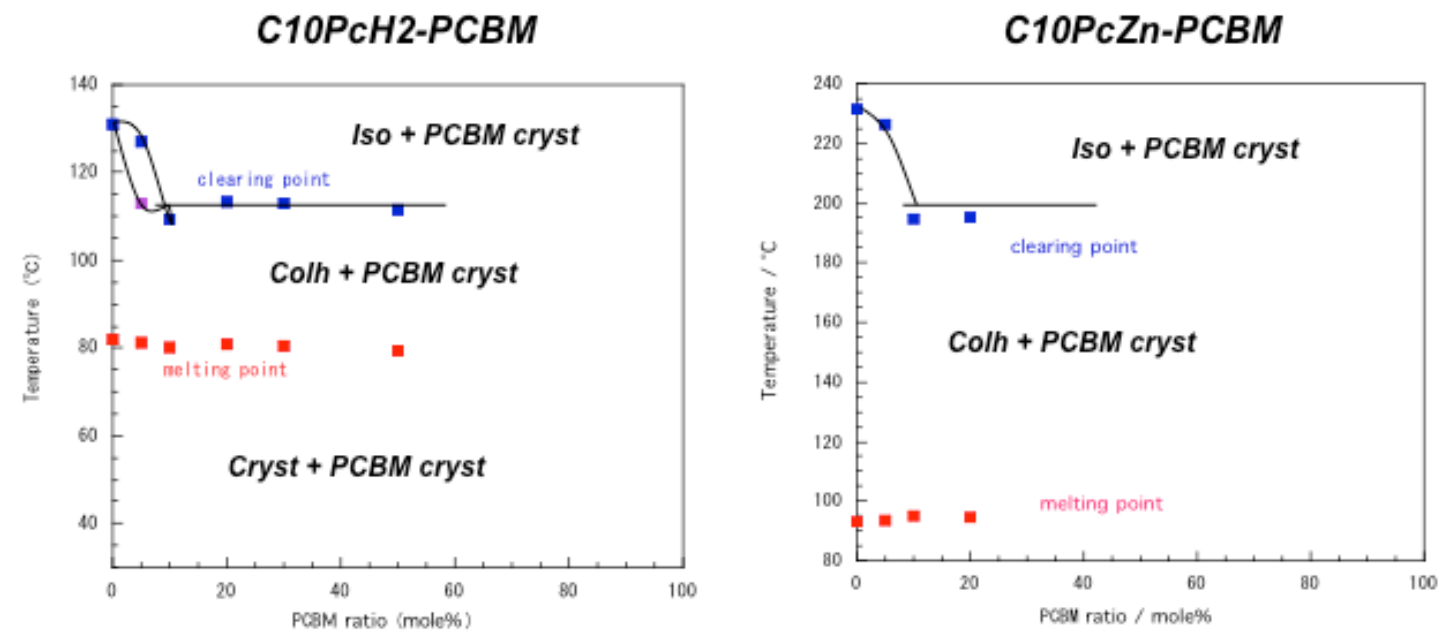

FIGURE 9 : Binary phase diagrams of $\mathrm{C} 10 \mathrm{PcH}_{2}$ / PCBM and C10PcZn / PCBM systems. 
compounds are in the order of $10^{-1} \mathrm{~cm}^{2} \mathrm{~V}^{-1} \mathrm{~s}^{-1}$. However, the repetitive heating and cooling treatment of the binary systems could lead to the recovering of mobility to the original level. These results indicate that the blend of $\mathrm{C} 10 \mathrm{PcH}_{2}$ and $\mathrm{C} 10 \mathrm{PcZn}$ exhibits a $\mathrm{Col}_{\mathrm{h}}$ mesophase in which the single component columns of $\mathrm{C}_{10 \mathrm{PcH}_{2}}$ and $\mathrm{C} 10 \mathrm{PcZn}$ coexist independently to make efficient paths for charge transport. Miscibility of LCs may provide a new tool for the better lightharvesting properties in OPV studies in which electronic transport also can be efficient. Also an importance to know the factors affecting miscibility of PCBM into Col mesophase of Pc mesogens is enhanced for making the better charge transport path as well as the more efficient $\mathrm{p} / \mathrm{n}$ heterojunction in the system. Miscibility for LC materials may have a glance to a future technology in organic electronics. ${ }^{[15]}$ Further studies are now under progress.

\section{ACKNOWLEDGMENTS}

This study was carried out by a financial support, in part by JST-ALCA (Japan Science and Technology Agency, Advanced Low Carbon Technology Research) Program.

\section{REFERENCES}

1. C. Destrade, N. -H. Tinh, H. Gasparoux, J. Malthete and A. M. Levelut, Mol. Cryst. Liq. Cryst., 1981, 71, 111.

2. $\quad$ N. Karl, Organic Electronic Materials, R.Farchioni and G. Grosso Eds., Springer, 2001.

3. a) W. Pisula, M. Zorn, J. -Y. Chang, K. Müllen and R. Zentel, Macromol. Rapid Commun., 2009, 30, 1179; b) S. Sergeyev, W. Pisula and Y. H. Geerts, Chem. Soc. Rev., 2007, 36, 1902 ; c) S. Laschat, A. Baro, N. Steinke, F. Giesselmann, C. Hägele, G. Scalia, R. Judele, E. Kapatsina, S. Sauer, A. Schreivogel and M. Tosoni, Angew. Chem. Int. Ed., 2007, 46, 4832.

4. L. Schmidt-Mende, A. Fechtenkötter, K. Müllen, E. Moons, R. H. Friend, and J. D. MacKenzie. Self-Organized Discotic Liquid Crystals for High-Efficiency Organic Photovoltaics, Science, 2001, 293, 1119.

5. J. J. M. Halls, C. A. Walsh, N. C. Greenham, E. A. Marseglla, R. H. Friend, S. C. Moratti and A. B. Holmes : Nature, 1995, 376, 498.

6. N. B. McKeown, Phthalocyanine Materials, Cambridge University Press, 1998.

7. H. Iino, Y. Takayashiki, J. Hanna and R. J. Bushby, Jpn. J. Appl. Phys., 2005, 44, L1310; H. Iino, J. Hanna, R. J. Bushby, B. Movaghar, B. J. Whitaker and M. J. Cook, Appl. Phys. Lett., 2005, 87, 132102.

8. Y. Miyake, Y. Shiraiwa, K. Okada, H. Monobe, T. Hori, N. Yamasaki, H. Yoshida, M. J. Cook, A. Fujii, M. Ozaki and Y. Shimizu, Appl. Phys. Express, 2011, 4, 021604.

9. T. Hori, Y. Miyake, N. Yamasaki, H. Yoshida, A. Fujii, Y. Shimizu and M. Ozaki, Appl. Phys. Express, 2010, 3, 101602 .

10. M. J. Cook, M. F. Daniel, K. J. Harrison, N. B. McKeown and A. J. Thomson, J. Chem. Soc., Chem. Commun., 1987, 1086; M. J. Cook, S. J. Cracknell and K. J. Harrison, J. Mater. Chem., 1991, 1, 703.

11. a) J. C. Swarts, E. H. G. Langner, N. Krokeide-Hove and M. J. Cook., J. Mater. Chem., 2001, 11, 434 ; b) M. J. Cook, M. F. Daniel, K. J. Harrison, N. B. McKeown and A. J. Thomson, J. Chem. Soc., Chem. Commun., 1987, 1086.

12. Y. Shimizu, In Supramoelcular Soft Matter, T. Nakanishi Ed., Wiley, 2011.

13. F. Nekelson, H. Monobe, M. Shiro and Y. Shimizu, J. Mater. Chem., 2007, 17, 2607.

14. F. Nekelson, K. Miyamoto, Q.-D. Dao, T. Hori, T. Nakao, H. Yoshida, A. Fujii, M. Ozaki and Y. Shimizu, in preparation for submission.

15. Y. Shimizu, In Nanoscience of Liquid Crystals- From Self-Organized nanostructures to Applications, Q. Li Ed., Springer, 2014. (ISBN: 978-3-319-04866-6).

*yo-shimizu@aist.go.jp; phone 8172 751-9525; fax 8172 751-9628 